van- and car-pools, buses, trolleys, and trains, and discourage driving (usually alone) to and from work, would help to reduce carbon dioxide emissions as well as break up traffic gridlock, cut road fatalities, and make the air more breathable.

- Cut other 'greenhouse gas' emissions. The car 'population boom' has largely wiped out the overall effect of reductions in per-car pollution. Requiring advanced pollution controls of all vehicles would limit growth in carbon monoxide, hydrocarbon, and nitrogen oxide, emissions for a few decades.

Driving Forces provides a compelling argument that expected increases in emissions of carbon dioxide, one of the most important 'greenhouse gases', from motor vehicles world-wide, will make it exceedingly difficult to curb global climate change. The Authors project motorvehicle growth throughout the world together with the implications for future emissions, and also analyse the relative contributions to global warming from vehicles in both the industrialized and developing worlds.

World-wide, the number of motor vehicles is growing faster than the global population. Over the last forty years, the global vehicle population has grown tenfold and could double in the next two decades. While the growth-rate of motor vehicles in highly industrialized countries has slowed, population growth and increased urbanization and industrialization are accelerating the use of motor vehicles elsewhere.

In the $1988-95$ period, particularly high growth in vehicle use is expected in the Asia-Pacific region (96\%, excluding Japan), Africa and the Middle East (40\%), the Eastern Bloc (31\%), and Latin America (17\%).

Carbon dioxide emissions from motor vehicles have grown by about $3 \%$ per year for the last twenty years, and now account for about $14 \%$ of carbon dioxide emissions from fossil-fuel burning world-wide. The United States alone accounts for about $38 \%$ of the world's total carbon dioxide emissions from motor vehicles. Present trends suggest that, unless steps are taken to reverse this growth, carbon dioxide emissions from motor vehicles worldwide could increase between $20 \%$ and $50 \%$ over the next twenty years.

The Authors offer a strong case for increased new-car efficiency and tightened pollution standards being only temporary mensures. Recent US history clearly demonstrates that the tangible benefits from technological improvements can be cancelled out by more vehicles being driven more kilometres. Despite a successful effort to double US new car fuel-efficiency between 1974 and 1988, the amount of gasoline consumed by cars in 1988 was still $6 \%$ higher than in 1970 . Consumption by cars, trucks, and buses, grew by more than $40 \%$ during that period, with a resulting increase in carbon dioxide emissions from vehicles.

Internationally, efficiency gains have also been overwhelmed by growth in the number of kilometres driven. Between 1973 and 1987, the average amount of fuel consumed per vehicle world-wide decreased by about $20 \%$. Yet total consumption rose by about $40 \%$, driven by a $70 \%$ increase in the number of vehicles.

'Without question, coping with global warming and the risks of dependence on foreign oil will require an international push towards vehicles that emit no pollution whatever and are not petroleum-powered,' the Authors conclude. 'Producing them should be a high public priority, not only in the United States, but also in Japan and Europe, where $80 \%$ of today's motor-vehicles are manufactured.'

SHIRLEY GEER
World Resources Institute
1709 New York Avenue, NW
Washington
DC 20006, USA.

SHIRLEY GEER

1709 New York Avenue, NW $D C 20006, U S A$

\title{
Chair of Ecological Philosophy Established in Warsaw, Poland
}

Poland needs help in recovering from devastations which were not only economic but also cultural. Among other things, Poland needs to revitalize its educational system. A key move in this direction could turn out to be the establishment very recently of a Chair of Ecological Philosophy, sponsored by three major Polish Universities and aspiring to become a centre of ecological awareness on the European, and perhaps even on the world, scale. It is the ambition of the Polish education authorities to make it stand out as the first endowed chair in Eastern Europe and a 'model of excellence' for all Polish and Eastern European universities.

To endow a chair fully in Poland would cost about US $\$ 250,000$, which is a considerable sum of money, yet is only about one-sixth of the cost of endowing a chair in the USA. As is the case with endowed chairs in the USA, the Chair will be supported by the interest from the invested endowment. The money will be invested in a British bank, and a board of trustees will oversee the activities and accountability of the Chair.

The Chair will engage in research and teaching activities, as most university chairs do. Yet given the state of ecological devastation of Poland, the importance of the Chair, through the knowledge it will propagate, should far exceed in effect the usual scholarly endeavours of most university chairs. The Chair will organize interna- tional conferences on appropriate topics - probably biennially. Of them the first will be that of 1991 which is already outlined, with the Dalai Lama opening the event. The Chair will need some financial support to cover the expenses of this conference - US $\$ 25,000$ for travel expenses of the principal speakers.

The Chair will publish a quarterly journal provisionally entitled 'Gaia' - Dialogues on Eco-consciousness and Eco-ethics. In the manner of most newly-established journals, it will need some financial support during the first two years of its publication - approximately US $\$ 12,000$.

The Polish education authorities will provide the physical space for the Chair. The remaining items, such as computers, faxes, and periodicals (as well as the 'green' library), will need to be financed from external sources.

Nowadays, no one will doubt that saving the Earth is one of the highest priorities of the human species. Yet we humans are, by and large, not fully aware that to bring about lasting solutions to our present environmental crises, we need far more than regulations to control air and water pollution: We need to think differently, to perceive differently, and to be guided by new, ecologicallysound values.

Thus, to accomplish a deeper and lasting reconstruction, we need centres of new awareness - centres of dissemination of ecological knowledge and its relationship to all other 
concerns. Such knowledge I call Ecological Philosophy. The creation of this first Chair of Ecological Philosophy is an act of courage and wisdom; perhaps in the future it will come to be considered an act of far-sighted prudence.

Poland needs help and the environment needs help. Poland has been in the forefront for political change in recent years, experimenting with models that others, expecially those in Eastern Europe, have followed. Now Poland embarks on yet another experiment - this time in the sphere of education. Would it be too much to expect that enlightened and concerned people and foundations will help Poland in this new venture, which is as bold as it is innovative, and of potential importance to us all?

HENRYK K. SKOLIMOWSKI, Professor
University of Michigan
College of Engineering Program in Humanities
550 East University Avenue
Ann Arbor
Michigan $48109-1092$
USA.

\section{The WHO Global Programme on AIDS}

The World Health Organization (WHO) Global Programme on AIDS (GPA) coordinates and directs the global fight against AIDS. WHO is responsible for the implementation of the three objectives of the Global AIDS Strategy, namely: (1) to prevent HIV infection, (2) to reduce the personal and social impact of HIV infection, and (3) to unify national and international health efforts. WHO's Global AIDS Strategy has received the support of practically every country in the world, of the World Health Assembly, of the United Nations General Assembly, and of the World Summit of Ministers of Health on Programmes for AIDS Prevention.

Global activities of GPA include organizing and cosponsoring technical and scientific meetings and consultations on research and policy issues. In 1990, activities of GPA required a total of US $\$ 90.7$ millions. About 50 per cent of this amount was obligated to support countrybased programmes.

In order to meet the challenge of AIDS in the coming decades, especially as it affects the 'developing world', the four priority aspects of WHO policy are: (1) strengthening collaboration with national AIDS control programmes; (2) focus on, and acceleration of, concomitant research and development activities; (3) preventing complacency and denial which threaten to undermine current actions and seriously to hamper future efforts; and (4) reinforcing effectiveness in the area of human rights.

S. Holck, Policy Coordinator
World Health Organization
20 Avenue Appia
1211 Geneva 27
Switzerland.
World Health Organization 1211 Geneva 27 Switzerland.

\section{OECD Countries Begin Cooperative Safety-testing on Chemicals}

Member countries of the Organization for Economic Cooperation and Development (OECD) have agreed to share out the work of testing a first group of 42 industrial chemicals that are produced in high volume. The decision, taken at a meeting of industry and government experts during 12-15 November 1990, follows an earlier decision, taken in April 1990, to collect information, evaluate it, and where necessary carry out, on a cooperative basis, new testing on the High Production Volume (HPV) industrial chemicals for which only limited environmental and safety data are available. Agreement was reached on future work as follows:

- for five chemicals, the data available, mainly from industry files, was judged sufficient to allow an initial assessment of their hazard potential;

- for 37 other chemicals, specific testing will be undertaken in 1991, in most cases by industry. This will include extensive tests for health-related parameters such as genotoxic and reproductive effects as well as any environmental risks.

This cooperative OECD work relies heavily on the voluntary cooperation of chemical companies which are providing privately-held data, and are also undertaking the specific testing required. The long-term objective of the programme is to ensure that there is an evaluation of the potential hazards of each of the chemicals produced in high volume (HPV chemicals). Based on such an eva- luation, national and, as appropriate, international action to reduce any risks stemming from use of these chemicals will be undertaken when necessary.

The programme is expected to address altogether some 1,500 HPV chemicals which have been identified by Member countries as being produced in quantities exceeding 1,000 tonnes per year world-wide. Work on testing the next group of about 100 priority HPV chemicals will begin in mid-1991. The OECD Business and Industry Advisory Committee (BIAC), and national chemical industry federations, have been of great assistance in promoting the collection of pertinent data.

The data compiled in this OECD Programme will be made available world-wide through the United Nations International Register of Potentially Toxic Chemicals and International Programme on Chemical Safety. Quite apart from the benefits accruing to public health and the environment, the cooperative safety-testing agreement will substantially alleviate the financial costs involved, and will also take account of animal welfare, as countries will share the work and accept each other's testing results.

Organization for ECONOMIC COOPERATION AND DEVELOPMENT

2 rue André-Pascal

75775 Paris Cedex 16

France. 